\title{
Inḩalts= Derzeidhni
}

I Derice

I. Beridt uber ben 40. Eugemeinen Benoffenidaftstag . . . 1 Prä̧entifile . . . . . . . . . . . . . . . . 1

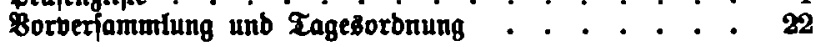

II. ¿uşzug aus ben Bexbanblungen bes Cenoffeníaftstages . . 28

Erfte $\mathfrak{z a u p t b e r f a m m l u n g . ~}$

Eröfinung, Anfpraden, Begrïßungen 28, 34, 35, 36, 37, 38,

Bemeinfame Angelegengeiten.

Beridt be Gutwalt. . . . . . . . . . . . 44

Die Bejesgebung und bie Benofieníaften. - Bortrag. 69

Peridgt iber bie Gilfafajle unb Rubegegaltstaffe beutidiner

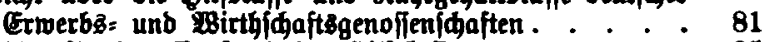

Wablen fâr ben Borfand ber Silfataffe. . . . 85

Dejoluffaffung uber ber Drt bes Eerofienidaftstages tm Jabre 1900.............. 85

3reite $\mathfrak{y} a$ ptoerfammlung.

A. Angelegenbeiten ber Arebitgenofferidaften.

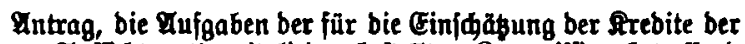
Quffidtşratbimitglieber beftellten fommiffion betreffenb Antrag, betreffenb Einridtungen zur Rontrole ber Spar=

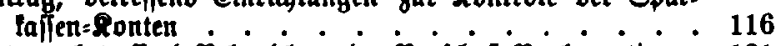

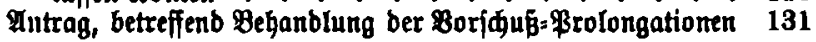

B. Angelegengeiten ber Ronfumbereine.

Beridt aีber bie Entwiđlung beß gemeinfdaftliden $28 a a r e n=$ eintaufz . . . . . . . . . . . . . . 142

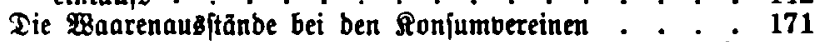

Mittheilungen aug ben einzelnen unterberbănben ūber mit

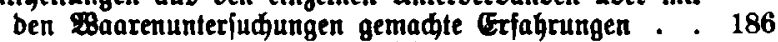

Tie Taraberednung bei ben verídiebenen fortiegung bei ber 3. Qauptberfammlung 209

C. Angelegengeiten ber Baugenoffenidaften.

Beipredung bon Bertretern bon Baugenofienidaften unb Baul unb Sparbereinen. . . . . . . . . 205 


\section{VII \\ Fritte Sauptberfammlung. \\ Ecite \\ Fortięung von}

B. Angelegenbeiten ber Monjumbereine.

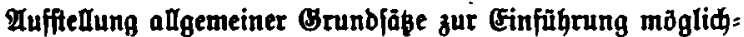
fter Einbeitlidfeit bei ben gebrudten Beridten ber Ronfumbereine.

Fortięung von

Bemeinfame Angelegenteiten.

Abänderung bes Statuts beg AIfgemeinen Berbanbes . . 223

Empjehlung ber Bilbung eines Ched=\$erbanbes . . . . 230

50 Jahre beutider Benoffenidaft 8 gefdidte. - Bortrag . 254

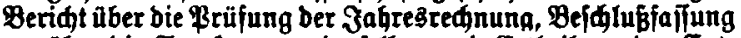
über bie Anertennung berjelben und Grtheifung ber Ent: laftung ............... . .

Beriat taber ben Boraniळlag ber (Finnahmen unb Musgaben für bas Jabr 1900 .

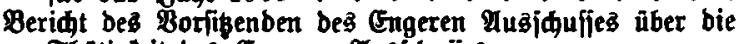

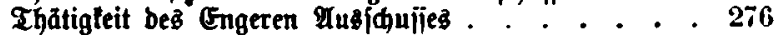
\$ahl von Mitgliebern in ben Engeren $\mathfrak{A} u \hat{B} \mid \dot{\phi} u \dot{\beta}$. . . 277

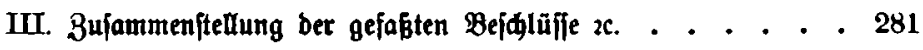

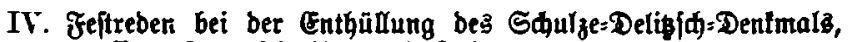

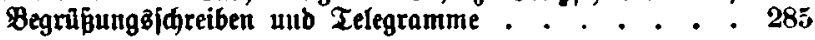

V. Beridt über bie Berbanblungen ber Berbanbsirebijoren • . 305

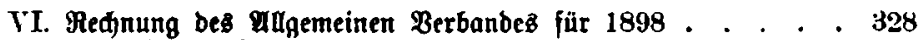
Boranjíläge für 1899 und 1900 . . . . . . . . . . 337

VI. Beridt über Mitglieberbejtand und Mitglieberbewegung in Ä agemeinen Berbanbe . . . . . . . . . . . . 339 Siite ber Benoffenidjaften bes Magemeinen Berbanbes unb Beitragslifte. . . . . . . . . . . . . $3 \$ 1$

Bujammenjteûung ber Unterberbånde. . . . . . . . . . 425

VIII. Rifte ber Berbanosgenofienidaften nad bem 2(iplabet und nad) Benofieniфaftagattunger . . . . . . . . . . 427

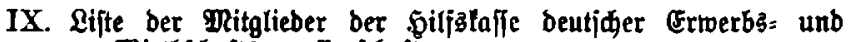

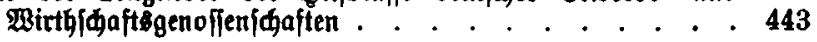

\&iteraturberzeiđniß̧. . . . . . . . . . . . . 452

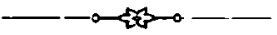

